\title{
Assessment and an updated list of the mosquitoes of Saudi Arabia
}

\author{
Azzam M. Alahmed ${ }^{1}$, Kashif Munawar ${ }^{1 *}$, Sayed M. S. Khalil ${ }^{1,2}$ and Ralph E. Harbach ${ }^{3}$
}

\begin{abstract}
Background: Mosquito-borne pathogens are important causes of diseases in the Kingdom of Saudi Arabia. Knowledge of the mosquito fauna is needed for the appropriate control of the vectors that transmit the pathogens and prevent the diseases they cause. An important first step is to have an up-to-date list of the species known to be present in the country. Original occurrence records were obtained from published literature and critically scrutinized to compile a list of the mosquito species that occur within the borders of the Kingdom.

Results: Fifty-one species have been recorded in the Kingdom; however, the occurrence of two of these species is unlikely. Thus, the mosquito fauna of the Kingdom comprises 49 species that include 18 anophelines and 31 culicines. Published records are provided for each species. Problematic records based on misidentifications and inappropriate sources are discussed and annotated for clarity.
\end{abstract}

Conclusion: Integrated morphological and molecular methods of identification are needed to refine the list of species and accurately document their distributions in the Kingdom.

Keywords: Culicidae, Mosquitoes, Saudi Arabia, Vectors

\section{Background}

The Arabian Peninsula (c.3 million $\mathrm{km}^{2}$ ) includes the Kingdom of Saudi Arabia (KSA), Oman, Qatar, United Arab Emirates and Yemen. The KSA occupies the major portion of the peninsula $\left(c .1 .97 \mathrm{~m} \mathrm{~km}^{2}\right)$, and includes 13 provinces. Mosquito-borne pathogens cause several diseases in the KSA. Malaria has been considered an endemic disease in the country from as early as 1900 [1].

Many studies have focused on the identification and ecology of the mosquito fauna of the peninsula, including the KSA [2-7]. The distribution and abundance of mosquito species are influenced by host availability and human activities, changes in land cover and climatic conditions, such as temperature and rainfall [8]. These conditions significantly affect the vectorial capacity of anopheline and other mosquitoes for pathogen transmission. Understanding these factors is essential for disease control.

\footnotetext{
*Correspondence: kmunawar@ksu.edu.sa

${ }^{1}$ Plant Protection Department, College of Food and Agricultural Sciences,

King Saud University, Riyadh, Saudi Arabia

Full list of author information is available at the end of the article
}

Mosquito-borne pathogens, including Plasmodium species, dengue virus, Rift Valley fever virus and microfilariae, cause diseases in the KSA [9-11]. Correct identification of vector species and knowledge of their distributions and biology are important requirements for disease control.

Historically, mosquitoes have been collected in different areas of the KSA during ecological studies and for construction of morphological keys for their identification. Prior to 1956 [2], little was known about the mosquito fauna of the Arabian Peninsula, with virtually nothing known about mosquitoes in the central and northern regions of the peninsula. Records of mosquito species collected in the KSA are found principally in papers published before the end of the last century [2, $4,5,12-14]$. Additional species have been recorded in more recent publications, but until now a list of all species of mosquitoes present in the country has not been published. Therefore, the purpose of this work was to produce an up-to-date list of the mosquito species that are definitely known to occur in the KSA, annotated with published collection records. 


\section{Methods}

PubMed, ResearchGate, Saudi Digital Library and Scopus were searched for articles on the Culicidae of Saudi Arabia using the terms "mosquito" and "Saudi Arabia" separately and in combination. Articles recovered from the search were used as a source of possible additional articles. All references obtained from the searches were examined for species and collection records, and the data were recorded in a spread sheet. The data were used to compile an up-to-date list of the mosquito species that are unequivocally known to occur in the KSA. The abbreviations for genera in the S3 Appendix of Wilkerson et al. [15] are used herein.

\section{Results}

Search of the literature revealed that 51 mosquito species have been found in the KSA from 1956 to 2017. However, the occurrence of two of these species in the country is doubtful (see "Discussion"), leaving 49 species (18 anophelines and 31 culicines). The anophelines include proven or suspected vectors of malarial protozoa and the culicines include proven or suspected vectors of dengue fever, chikungunya, Zika, yellow fever, West Nile and Rift Valley fever viruses, as well as microfilariae. The 49 species are listed below. The listing is arranged alphabetically by genus, subgenus and species. The aedine species are listed as species of Aedes in accordance with the classification of Wilkerson et al. [15]; anopheline and nonaedine species are listed under the generally accepted genera and subgenera recognized in the online Mosquito Taxonomic Inventory (http://mosquito-taxonomic-inven tory.info/). Published records are listed for each species, some with brief notes for clarification.

\section{List of the mosquito species known to occur in the KSA}

\section{Genus Aedes Meigen, 1818}

\section{Subgenus Aedimorphus Theobald, 1903}

1. Ae. (Aedimorphus) vexans (Patton, 1905)

Records: [2] (as Ae. arabiensis); [6, 16] (as Aedimorphus v. arabiensis), [17-23] (as Aedimorphus arabiensis); [24, 25]; [26] (as Ae. vexans).

\section{Subgenus Fredwardsius Reinert, 2000}

2. Ae. (Fredwardsius) vittatus (Bigot, 1861)

Records: [6, 16, 23] (as Fredwardsius vittatus); [17] (as species of subgenus Aedimorphus); [18, 21, 24, 25, 27, 28].

\section{Subgenus Ochlerotatus Lynch Arribálzaga, 1891}

3. Ae. (Ochlerotatus) caballus (Theobald, 1912)

Records: [17] (as Ochlerotatus caballus); [24]; [27].

4. Ae. (Ochlerotatus) detritus (Haliday, 1833)

Records: [6, 7] (as Ochlerotatus detritus).

5. Ae. (Ochlerotatus) caspius (Pallas, 1771)
Records: [2, 18-20, 24-26, 28-40]; [6, 7, 16, 17] (as Ochlerotatus caspius).

\section{Subgenus Stegomyia Theobald, 1901}

6. Ae. (Stegomyia) aegypti (Linnaeus, 1762)

Records: [2, 18, 20, 21, 24, 25, 27, 28, 30, 34, 41-49]; [6, 7, 16, 23, 26] (as Stegomyia aegypti).

7. Ae. (Stegomyia) unilineatus (Theobald, 1906)

Records: [21, 24, 50].

\section{Genus Anopheles Meigen, 1818}

Subgenus Anopheles Meigen, 1818

8. An. (Anopheles) coustani Laveran, 1900

Records: [2, 3, 14, 51-54].

9. An. (Anopheles) tenebrosus Dönitz, 1902

Records: [1, 6, 14, 24, 29, 31, 35]; [2, 55] (as An. coustani var. tenebrosus).

\section{Subgenus Cellia Theobald, 1902}

10. An. (Cellia) arabiensis Patton, 1905

Records: [1, 16, 22, 26, 56-59]; [2, 6, 30, 35, 51] (as An. gambiae); [3, 24] (as An. arabiensis and An. gambiae (s.l.)); [7, 13, 14, 27, 29]; [12, 60] (as An. gambiae species B); [61, 62] (as An. gambiae (s.l.)).

11. An. (Cellia) azaniae Bailly-Choumara, 1960

Records: [7, 17, 18, 24, 32].

12. An. (Cellia) cinereus Theobald, 1901

Records: [2, 3, 6, 7, 14, 16, 18-20, 24, 28, 34, 35, 59, 61].

13. An. (Cellia) culicifacies Giles, 1901 (s.l.)

Records: [3, 28] (as An. culicifacies adenensis); [6, 24, 61]; [13] (as An. culicifacies probably species A); [16] (as An. culicifacies (s.l.)).

14. An. (Cellia) dthali Patton, 1905

Records: [1, 3, 18, 20, 26, 28, 30, 34, 35, 41, 44, 57] (as An. d'thali); $[2,6,7,14,16,21,22,24,27,32,39,51,56,59$, 61]; [19] (as An. d<thali); [33] (as An. azaniae? and An. d'thali).

15. An. (Cellia) fluviatilis James, 1902 (s.l.)

Records: [1, 2, 12, 14, 24, 26, 31, 35, 37, 51, 55, 57].

16. An. (Cellia) multicolor Cambouliu, 1902

Records: $[1-3,6,7,14,16,19,22,24,27-30,32-36,40$, 41, 51, 55-57].

17. An. (Cellia) pharoensis Theobald, 1901

Records: [2, 3, 14]; [51] (misspelled as phorensis).

18. An. (Cellia) pretoriensis (Theobald, 1903)

Records: [3, 6, 14, 18, 24, 26-29, 32, 35, 39, 56, 58].

19. An. (Cellia) pulcherrimus Theobald, 1901

Records: [2, 12, 14, 24, 55].

20. An. (Cellia) rhodesiensis rupicolus Lewis, 1937

Records: [1, 3]; [14, 24, 56, 59] (as rupicola); [22, 27] (as An. rupicolus); [28, 57]; [30, 35] (as An. rhodesiensis); [33] (as An. azaniae? and An. rhodesiensis); [51] (as An. rhodesiensis, misspelled as rohesiensis). 
21. An. (Cellia) sergentii (Theobald, 1907)

Records: [1-3, 6, 12-14, 16, 22, 24, 27, 29, 31, 35, 5557, 61, 62]; [7, 30, 37, 51] (as sergenti).

22. An. (Cellia) stephensi Liston, 1901

Records: [1, 2, 6, 12-14, 18-20, 23, 24, 28, 30, 32-35, 37, 39, 51, 55, 59].

23. An. (Cellia) subpictus Grassi, 1899 (s.l.)

Records: [6, 20, 24, 28, 30, 32, 33, 35, 51, 61].

24. An. (Cellia) superpictus Grassi, 1899

Records: [1, 7, 12, 14, 19, 20, 28, 34, 35].

25. An. (Cellia) turkhudi Liston, 1901

Records: $[1-3,6,7,14,16,20,22,24,26-28,30,32,33$, $51,56,57,61]$.

\section{Genus Culex Linnaeus, 1758}

\section{Subgenus Barraudius Edwards, 1921}

26. Cx. (Barraudius) pusillus Macquart, 1850

Records: [2, 6, 24, 32, 34-36, 40].

\section{Subgenus Culex Linnaeus, 1758}

27. Cx. (Culex) decens Theobald, 1901

Records: [16, 24, 26, 63]; [64] (requires confirmation).

28. Cx. (Culex) duttoni Theobald, 1901

Records: [7, 16, 22, 24, 63]; [64] (requires confirmation).

29. Cx. (Culex) laticinctus Edwards, 1913

Records: [2, 4-7, 16, 18-20, 24, 28, 30, 32, 34, 35, 39, 64].

30. Cx. (Culex) mattinglyi Knight, 1953

Records: [4-6, 16, 24, 32].

31. Cx. (Culex) mimeticus Noè, 1899

Records: $[4,7,16,24]$.

32. Cx. (Culex) perexiguus Theobald, 1903

Records: $[4,5,16,20,24,28,36,40,41] ;[6,19,32,33,35$,

39] (as Cx. perexiguus and Cx. univittatus); [31, 34, 64] (as Cx. univittatus).

33. Cx. (Culex) pipiens Linnaeus, 1758

Records: [2] (as Cx. pipiens and Cx. pipiens var. molestus); [4, 5, 24, 65]; [6] (undoubtedly includes $C x$. quinquefasciatus and hybrids); [7] (may be misidentification of Cx. quinquefasciatus); [19, 34, 64] (Cx. pipiens and Cx. quinquefasciatus =hybrids?); [20, 28, 53] (may be or include Cx. quinquefasciatus); [23] (probably includes Cx. quinquefasciatus); [26] (may be misidentification of Cx. quinquefasciatus); [30, 33, 36, 40, 44] (probably hybrids); [31] (as Cx. pipiens complex=hybrids?); [35] (probably includes hybrids?); [37] (as Cx. molestus); [41, 66] (northern west coastal localities only); [67] (as $C x$. pipiens and $C x$. quinquefasciatus, probably includes hybrids).

34. Cx. (Culex) quinquefasciatus Say, 1823

Records: [2] (as Cx. pipiens ssp. fatigans); [4, 5, 7, 24, 26, 28, 31, 65]; [6, 30, 38] (probably includes hybrids); [16] (as Cx. pipiens and Cx. quinquefasciatus); [17, 21,
22] (as Cx. pipiens complex); [18] (may be or include $C x$. pipiens); $[19,29]$ (as $C x$. pipiens $=$ hybrids? and $C x$. quinquefasciatus); [20, 23] (may include $C x$. pipiens); $[32,39]$ (as Cx. pipiens and Cx. quinquefasciatus, probably includes hybrids); [33] (may include hybrids); [34, 64] (probably hybrids); [35] (in southern areas of eastern region); [41, 66] (mid-west coastal area only, probably includes hybrids); [44] (Cx. pipiens = hybrids and $C x$. quinquefasciatus).

35. Cx. (Culex) simpsoni Theobald, 1905

Records: [6] (southwest only); [16, 18] (may be or include Cx. sinaiticus); [24, 28].

36. Cx. (Culex) sinaiticus Kirkpatrick, 1925

Records: [4, 5, 20, 22, 24, 28, 30, 64]; [16, 18, 68] (may be or include Cx. simpsoni); [26] (may include or be misidentification of $C x$. simpsoni); $[32,39]$ (as $C x$. perexiguus and Cx. simpsoni); [33, 35] (as Cx. simpsoni); [61] (misidentification as $C x$. simpsoni in areas north of southwest). 37. Cx. (Culex) sitiens Wiedemann, 1828

Records: [2, 4, 5, 18, 22, 24, 26, 28, 41, 61].

38. Cx. (Culex) theileri Theobald, 1903

Records: [4, 5, 7, 16, 20, 24, 28, 29, 32, 33, 36, 37, 39, 41].

39. Cx. (Culex) tritaeniorhynchus Giles, 1901

Records: [4, 5, 7, 16-24, 26, 28, 30-36, 39, 41, 44, 45, 68]. 40. Cx. (Culex) univittatus Theobald, 1901

Records: [18] (may be or include Cx. perexiguus)]; [20] (requires confirmation, might be $C x$. perexiguus); [24, 28]; [30] (probably Cx. perexiguus); [36] (undoubtedly includes $C x$. perexiguus).

\section{Subgenus Culiciomyia Theobald, 1907}

41. Cx. (Culiciomyia) nebulosus Theobald, 1901

Records: [16, 21, 24, 37].

Subgenus Maillotia Theobald, 1907

42. Cx. (Maillotia) arbieeni Salem, 1938

Records: [7, 16, 28, 30, 36].

43. Cx. (Maillotia) salisburiensis Theobald, 1901

Records: [16, 21, 24].

\section{Subgenus Oculeomyia Theobald, 1907}

44. Cx. (Oculeomyia) bitaeniorhynchus Giles, 1901

Records: [16, 24, 26, 63].

\section{Genus Culiseta Felt, 1894}

\section{Subgenus Allotheobaldia Brolemann, 1919}

45. Cs. (Allotheobaldia) longiareolata (Macquart, 1838)

Records: [2, 16, 18-20, 23, 24, 26, 28, 30-36, 39-41].

\section{Subgenus Culiseta Felt, 1894}

46. Cs. (Culiseta) subochrea (Edwards, 1921)

Records: [24] (as Cs. annulata and Cs. subochrea); [29, 36, 40]; [31] (as ochracea annulata). 
Genus Lutzia Theobald, 1903

Subgenus Metalutzia Tanaka, 2003

47. Lt. (Metalutzia) tigripes (de Grandpre \& de Charmoy, 1901)

Records: [2, 18-20, 22, 30] (as Cx. tigripes); [7, 16, 24, 26, 36].

Genus Coquillettidia Dyar, 1905

48. Cq. (Coquillettidia) richiardii (Ficalbi, 1889)?

Record: [31] (as Mansonia sp.).

Genus Uranotaenia Lynch Arribálzaga, 1891 Subgenus Uranotaenia Lynch Arribálzaga, 1891 49. Ur. (Uranotaenia) unguiculata pefflyi Stone, 1961 Records: [7, 24, 31, 35] (as Ur. unguiculata); [69].

\section{Discussion}

The ecological diversity of the KSA allows multiple opportunities for the evolution of variation in both mosquitoes and their pathogens. Large-scale movements of people, including the annual pilgrimage to Mecca, largescale use of foreign workers and new developmental projects engender environmental heterogeneity and complex epidemiology. The wide variation in ecological settings may complicate the understanding of spatial/temporal characteristics and population dynamics of mosquito vectors of pathogens that cause diseases in humans.

Investigators may be reluctant to conduct ecological studies in the KSA because field work is labour-intensive and time-consuming. Moreover, due to habitat heterogeneity, which in the KSA is often extreme, there are species of only seven mosquito genera in the country. Here we present the first complete list (see above) of the mosquito species that definitely are known to occur in the KSA. In some cases, ecological and morphological studies have shown that some species are members of species complexes. There are members of four Anopheles species complexes in the country, including the An. gambiae, An. fluviatilis, An. culicifacies and An. subpictus complexes. The Afrotropical An. gambiae complex consists of eight species, which includes malaria vectors (An. gambiae, An. arabiensis, An. bwambae, An. coluzzii, An. merus and An. melas) and non-vectors (An. quadriannulatus and An. amharicus) [70, 71]. Anopheles arabiensis is the only member of the complex with a range that extends outside of Africa into the southwestern and western areas of the Arabian Peninsula, occurring in the KSA and Yemen, where it is the major malaria vector [2, 3, 7, 72-75]. Most ecological studies conducted in the KSA recorded the presence of An. arabiensis (often as An. gambiae) in different life stages [27, 29, 30, 51]. Moreover, molecular analysis based on the internal transcribed spacer (ITS2) region of rDNA has shown that An. arabiensis (GenBank:
KM068071) is the only member of An. gambiae complex present in the KSA [59].

The An. fluviatilis complex is a group of mosquitoes that is widely distributed in southern and southwestern Asia and includes important malaria vectors [76]. The complex includes four species informally denoted as species S, T, U and V [77-81]. Anopheles fluviatilis S is mainly anthropophilic, endophilic and a very competent malaria vector [52]. Species $\mathrm{T}$ and $\mathrm{U}$ are primarily zoophilic, exophagic and exophilic, and are regarded as poor- or non-vectors of malaria even though they are responsible for malaria transmission in mountainous and hilly areas in Asia, including Iran [80, 82]. Anopheles fluviatilis (s.l.) was recorded in the eastern and western regions of the KSA by Mattingly \& Knight [2], Wills et al. [31] and Al-Ghamdi et al. [51]. It is not known whether species $\mathrm{T}$ or $\mathrm{U}$ or both are present in the KSA.

The An. culicifacies complex consists of five sibling species, informally named species A, B, C, D and E, based on cytotaxonomic and molecular evidence [53, $76,83]$. These species have distinct geographical distributions, blood-feeding behaviour and vectorial capacity for malaria transmission $[54,84,85]$. The complex is widely distributed from southern China to Iran, the Arabian Peninsula and Ethiopia [86]. Species E is the most important malaria vector in the Indian subcontinent, and is highly anthropophilic and endophilic [87]. The other sibling species have low anthropophilic index or are highly zoophilic, and are considered poor- or nonmalaria vectors in India and Sri Lanka [52, 88]. Available data indicate there are at least two species of the complex in Iran [89], but only the presence of species A has been confirmed based on cytogenetic and molecular evidence; the second species may be a new member of the complex [90]. Further study is needed to determine which member or members of the complex are present in the KSA.

The An. subpictus complex consists of four species in India, informally denoted as species A, B, C and D, based on morphological, chromosomal and molecular differences [91, 92]. As is the case in Iran [90], it is not known which species of the complex is present in the KSA.

Anopheles stephensi is the main malaria vector in the eastern region of the KSA, but members of the An. fluviatilis and An. culicifacies complexes, which are important malaria vectors in other parts of Asia [2, 3, 55, 74], may contribute to malaria transmission. In Asia, $A n$. stephensi, An. culicifacies (s.l.) and An. fluviatilis (s.l.) consist of different ecoforms that are restricted to rural or urban areas with different degrees of involvement in malaria transmission [54, 76, 85]. Anopheles stephensi is a major vector in Asia and the Middle East, including, in addition to the eastern KSA, areas of Iran, Pakistan, Afghanistan, India and southern China [87]. It includes 
three ecological variants (egg phenotypes): the mysorensis, typical and intermediate forms, which are based and distinguished on egg morphology [87, 93-96]. The typical (type) form is mainly found in urban areas, whereas the intermediate and mysorensis forms are mainly found in rural environments [87]. The blood-feeding behaviour and role of these forms in malaria transmission varies in different geographical regions. In Iran, the type form is highly anthropophilic and a major malaria vector, whereas the mysorensis form is mainly zoophilic and a poor- or non-vector [97]. In contrast, the mysorensis form is an important malaria vector in India [98]. These differences might be due to the type of host available and the presence of certain mosquito genotypes with different host preference and susceptibility to malarial parasites. Molecular study using two different markers (ITS2 and $\operatorname{cox} 1$ ) did not reveal any differences between An. stephensi (ITS2, GenBank: KM052589; and cox1, GenBank: KJ528887-KJ528894) in two distant cities of the KSA (Al-Ahsaa and Dammam) where different phenotypes might be present [59].

Anopheles azaniae was first encountered in Saudi Arabia during the collection of mosquitoes for Rift Valley virus isolation in the Jizan Region [17], and subsequently collected in the same region by Alahmed et al. [18] and Khater et al. [7]. The record of this species in the Riyadh Region [32], which is a very large eastern region that shares its southern border with Yemen, requires confirmation. The record of this species in the more northerly western Al-Madinah Al-Munawarah Region [33] is doubtful and a probable misidentification of either $A n$. dthali or An. rhodesiensis rupicolus. Anopheles azaniae was previously known to occur in neighbouring Yemen [14], where two morphological forms were recently discovered, the typical form and a previously unrecognized form not immediately identifiable as An. azaniae [99]. A single specimen of the atypical form had a mixed human/ bovine blood meal, indicating that females are anthropophilic and should be considered a potential vector of malarial protozoa. It seems possible that further studies in the southwest of the KSA may detect the presence of the atypical form.

A species of the genus Coquillettidia collected in the Eastern Province of the KSA was identified as a species of Mansonia in the study of Wills et al. [31]. According to the online catalogue of the Walter Reed Biosystematics Unit [24], only two species of the tribe Mansoniini are known to occur in more or less arid countries of the Middle East, Cq. (Coquillettidia) buxtoni in Israel and Syria and Cq. (Coq.) richiardii in Iran, Syria and Turkey. With that in mind, it seems likely that the generic identification of Wills et al. [31] was based on keys available at the time, e.g. Mattingly [100], which treated Coquillettidia as a subgenus of Mansonia. In view of the proximity of eastern areas of the KSA to Iran, we are confident that the mosquitoes identified as a species of Mansonia by Wills et al. [31] were most likely specimens of $C q$. richiardii.

Many of the occurrence records for Cx. pipiens and $C x$. quinquefasciatus in the KSA are problematic. Culex pipiens generally occurs north of a line transecting the KSA between Jeddah in the west and Al-Hasa in the east. Culex quinquefasciatus occurs in the more southerly region of the Arabian Peninsula, with isolated populations of $C x$. pipiens occurring in the southwestern mountains [5]. Introgression occurs between the two species where their distributions overlap in central KSA (see figure 3 in Harbach [101]). Both species exhibit considerable variation in the larval and adult stages, and they cannot always be distinguished with certainty. They are only reliably distinguished by characters of the male genitalia; however, their separation is complicated by the occurrence of hybrid forms in the central transitional zone and eastern coastal region of the country. Hybrids are morphologically more variable than the parental species, and are only reliably distinguished from the parental species by the DV/D ratio calculated from measurements based on the form and relationships of the dorsal and ventral arms of the male genitalia [102, 103]. It is not possible to distinguish hybrid larvae and females from the parental species. For this reason, some hybrid specimens collected in and around the zone of introgression have undoubtedly been misidentified as either $C x$. pipiens or $C x$. quinquefasciatus. Larvae and adults collected north of the hybrid zone that have been identified as $C x$. quinquefasciatus are misidentified specimens of $C x$. pipiens, and those collected south of the zone that have been identified as Cx. pipiens, with the possible exception of those collected in the southwestern mountains, are misidentified specimens of $C x$. quinquefasciatus. Future studies based on dissections of male genitalia or DNA sequence analysis of larvae and adults are needed to substantiate species identifications and collection records. Culex quinquefasciatus is an important vector of the microfilariae that cause lymphatic filariasis.

Culex torrentium is listed as a species of the KSA in the online catalogue of the Walter Reed Biosystematics Unit [24] based on a number of reports, including Alahmed et al. [18, 19], Al Ahmed et al. [20, 28], Kheir et al. [34], Alahmed [35] and Hassan et al. [41]. However, it is obvious that the identification of $C x$. torrentium in the KSA by these authors is based on unreliable characters of larvae and adult habitus principally using the keys of Harbach $[4,5]$. This species can only be distinguished from members of the $C x$. pipiens complex with certainty based on features of the male genitalia. Additionally, $C x$. torrentium is a Palaearctic species whose distribution 
only extends south into Turkey and possibly into northern Iran [90, 104, 105]. As noted by Harbach [5], early records of $C x$. torrentium in Iraq are doubtful, and the species is not now listed as present in that country [106, 107]. For these reasons, $C x$. torrentium is excluded from the list of mosquito species known to occur in the KSA.

Four species of the subgenus Culex of the genus Culex occur in the southwestern Afrotropical Region of the Arabian Peninsula, i.e. Cx. decens, Cx. duttoni, $C x$. simpsoni and $C x$. univittatus. These species were only known to occur in Yemen $[5,108]$ until they were more recently found in the Asir Region [63], Jizan (Jazan) Region [18] and Najran Province [28], which border Yemen in the southwest corner of the KSA. The records of two of these species, $C x$. simpsoni and Cx. univittatus, require confirmation because their identification was based on larvae and adults. They are only reliably distinguished from $C x$. sinaiticus and $C x$. perexiguus, respectively, based on the morphology of the male genitalia. Records of the two species in more northerly areas of the country are more doubtful.

Since Culex salisburiensis has been known to be present in Yemen since 1953 [108], there is no reason to doubt its occurrence in the adjacent Afrotropical area of the KSA $[21,67]$. On the contrary, the reported finding of $C x$. wigglesworthi in the Asir Region by Al Ashry et al. [67] is certainly a misidentification. The authors collected 4307 Culex larvae, two of which were identified as $C x$. nebulosus, three as $C x$. perexiguus and two as $C x$. wigglesworthi. Larvae were identified using the keys of Hopkins [109], Mattingly \& Knight [2] and Harbach $[4,5]$. The identification of $C x$. nebulosus and $C x$. perexiguus may be correct as these two species are included in the keys of Mattingly \& Knight (Cx. nebulosus) and Harbach (Cx. nebulosus and Cx. perexiguus). Use of the badly outdated keys of Hopkins [109] for African species published in 1952, leading to the identification of $C x$. wigglesworthi, is problematic, nonetheless because it is a sub-Sharan species with closest records in southern Sudan, South Sudan and Kenya. Consequently, as it seems likely that the two larvae were misidentified specimens of either $C x$. perexiguus or $C x$. univittatus, Cx. wigglesworthi is excluded from the list of mosquito species known to occur in the KSA.

Alahmed [35], Alahmed et al. [36] and Khater et al. [7] recorded the presence of Uranotaenia (Pseudoficalbia) unguiculata in eastern and southwestern areas of the KSA. The authors, however, were apparently unaware of the earlier description of Ur. unguiculata pefflyi by Stone [69], and the recognized presence of only that form in eastern parts of the KSA [31]. Consequently, as it is unlikely that the typical form, $U r$. unguiculata unguiculata, is present in the country, only the subspecies described and named by Stone [69] is included in the list.

\section{Conclusions}

It is obvious from this study that researchers working in the KSA have generally been unaware of the limitations of available keys, have failed to critically evaluate published records and, at least in the case of Culex, have not confirmed identifications with correlated diagnostic features of the male genitalia. Future studies in the KSA must overcome these shortcomings by individually rearing larvae to obtain adults of both sexes for integrated morphological and molecular study, and use the resultant unequivocal molecular markers for the identification of larvae and adults collected in subsequent studies. Based on currently available information, it is concluded that 49 species of Culicidae, 18 anophelines and 31 culicines, are present in various regions of the KSA.

\section{Acknowledgements}

The authors extend their sincere appreciation to the Deanship of Scientific Research at King Saud University for supporting the work through College of Food and Agriculture Sciences Research Center

\section{Authors' contributions}

AMA realized the need for this study. KM and SMSK drafted the manuscript. $\mathrm{KM}$ and REH critically revised the manuscript for intellectual and taxonomic content. All authors read and approved the final manuscript.

\section{Funding}

This work was supported by the Deanship of Scientific Research at King Saud University through College of Food and Agriculture Sciences Research Center.

Availability of data and materials

Not applicable.

Ethics approval and consent to participate

Not applicable.

Consent for publication

Not applicable.

\section{Competing interests}

The authors declare that they have no competing interests.

\section{Author details}

1 Plant Protection Department, College of Food and Agricultural Sciences, King Saud University, Riyadh, Saudi Arabia. ${ }^{2}$ Agricultural Genetic Engineering Research Institute, Agricultural Research Center, 9 Gamaa Street, Giza, Egypt. ${ }^{3}$ Department of Life Sciences, Natural History Museum, Cromwell Road, London SW7 5BD, UK.

Received: 24 October 2018 Accepted: 19 June 2019

Published online: 19 July 2019

\footnotetext{
References

1. Al-Seghayer SM, Kenawy MA, Ali OTE. Malaria in the Kingdom of Saudi Arabia: epidemiology and control. Sci J King Faisal Univ. 1999;1:6-22.

2. Mattingly PF, Knight KL. The mosquito of Arabia I. Bull Br Mus (Nat Hist) Entomol. 1956;4:91-141.
} 
3. Zahar AR. Vector bionomics in the epidemiology and control of malaria. Part 1. The WHO African Region and the Southern WHO Eastern Mediterranean Region. Section III: Vector bionomics, malaria epidemiology and control by geographical areas. (D) East Africa. (E) Eastern outer islands. (F) Southwestern Arabia. Geneva: Division of Vector Biology and Control \& World Health Organization, Malaria Action Programme; 1985.

4. Harbach RE. Pictorial keys to the genera of mosquitoes, subgenera of Culex and the species of Culex (Culex) occurring in southwestern Asia and Egypt, with a note on the subgeneric placement of Culex deserticola (Diptera: Culicidae). Mosq Syst. 1985;17:83-107.

5. Harbach RE. The mosquitoes of the subgenus Culex in southwestern Asia and Egypt (Diptera: Culicidae). Contrib Am Entomol Inst. 1988;24(1):vi + 1-236.

6. Al Ahmed AM, Sallam MF, Khuriji MA, Kheir SM, Azari-Hamidian S. Checklist and pictorial key to the fourth-instar larvae of the mosquitoes (Diptera: Culicidae) of Saudi Arabia. J Med Entomol. 2011;48:717-37.

7. Khater El, Sowilem MM, Sallam MF, Alahmed AM. Ecology and habitat characterization of mosquitoes in Saudi Arabia. Trop Biomed. 2013;30:409-27.

8. Delgado-Petrocelli L, Camardiel A, Aguilar VH, Martinez N, Córdova K, Ramos S. Geospatial tools for the identification of a malaria corridor in Estado Sucre, a Venezuelan north-eastern state. Geospat Health. 2011;5:169-76.

9. Alhaeli A, Bahkali S, Ali A, Househ MS, El-Metwally AA. The epidemiology of dengue fever in Saudi Arabia: a systematic review. J Infect Public Health. 2016;9:117-24.

10. Samy AM, Peterson AT, Hall M. Phylogeography of Rift Valley fever virus in Africa and the Arabian Peninsula. PLoS Negl Trop Dis. 2017;11:e0005226.

11. Hotez PJ, Savioli L, Fenwick A. Neglected tropical diseases of the Middle East and North Africa: review of their prevalence, distribution, and opportunities for control. PloS Negl Trop Dis. 2012;6:e1475.

12. Zahar AR. Review of the ecology of malaria vectors in the WHO Eastern Mediterranean Region. Bull World Health Organ. 1974;50:427-40.

13. Zahar AR. Vector bionomics in the epidemiology and control of malaria. Part II. The WHO European Region and the WHO Eastern Mediterranean Region. Volume I. Vector laboratory studies. Geneva: Division of Vector Biology and Control \& World Health Organization; 1988.

14. Glick JI. Illustrated key to the female Anopheles of southwestern Asia and Egypt (Diptera: Culicidae). Mosq Syst. 1992;24:125-53.

15. Wilkerson RC, Linton Y-M, Fonseca DM, Schultz TR, Price DC, Strickman DA. Making mosquito taxonomy useful: a stable classification of tribe Aedini that balances utility with current knowledge of evolutionary relationships. PLoS ONE. 2015;10:e0133602.

16. Al Ashry HA, Kenawy MA, Shobrak M. Fauna of mosquito larvae (Diptera: (ulicidae) in Asir Provence [sic], Kingdom of Saudi Arabia. J Egypt Soc Parasitol. 2014;44:171-84.

17. Jupp PG, Kemp A, Grobbelaar A, Leman P, Burt FJ, Alahmed AM, et al. The 2000 epidemic of Rift Valley fever in Saudi Arabia: mosquito vector studies. Med Vet Entomol. 2002;16:245-52.

18. Alahmed AM, Al Kuriji MA, Kheir SM, Al Haqawi HM, Sultan EAA. Mosquito (Diptera: Culicidae) and their seasonal activity in Jazan Region, Saudi Arabia. J Saudi Soc Agric Sci. 2010;9:136-8.

19. Alahmed AM, Al Kuriji MA, Kheir SM, Al Tamimi HSH, Tarad FS, Salih MM. Mosquito fauna (Diptera: Culicidae) of the northern region of Saudi Arabia and their seasonal activity. Saudi J Biol Sci. 2010;17:32.

20. Al Ahmed AM, Al Kuriji MA, Kheir SM, Al Zahrni AA. Distribution and seasonal abundance of different mosquito species (Diptera: Culicidae) in Al Bahah Region, Saudi Arabia. Arab Gulf J Sci Res. 2010;28:67-78.

21. Miller BR, Godsey MS, Crabtree MB, Savage HM, Al-Mazrao Y, Al-Jeffri $\mathrm{MH}$, et al. Isolation and genetic characterization of Rift Valley fever virus from Aedes vexans arabiensis, Kingdom of Saudi Arabia. Emerg Infect Dis. 2002;8:1492-4.

22. Abdoon AM, Ibrahim AA. Mosquito breeding habitats in Tihama lowlands of Asir region, Kingdom of Saudi Arabia. In: Proceedings of third conference of applied entomology. Cairo: Cairo University; 2005.

23. Al Ahmed AM, Badjah-Hadj-Ahmed A-Y, Al Othman ZA, Sallam MF. Identification of wild collected mosquito vectors of diseases using gas chromatography-mass spectrometry in Jazan Province, Saudi Arabia. J Mass Spectrom. 2013;48:1170-7.
24. Gaffigan TV, Wilkerson RC, Pecor JE, Stoffer JA, Anderson T. Systematic catalog of Culicidae. Suitland: Walter Reed Biosystematics Unit, Museum Support Center, Smithsonian Institution; 2019. http://www.mosquitoca talog.org/. Accessed 1 Apr 2019.

25. Alikhan M, Al Ghamdi K, Mahyoub JA. Aedes mosquito species in western Saudi Arabia. J Insect Sci. 2014;14:69.

26. Bakr RFA, Nassar MI, El-Barky NM, Kotb TF, Badrawy H, Abdeldayem MS. Prevalence of mosquitoes in Jazan Province, Saudi Arabia, Egypt. Acad J Biol Sci A Entomol. 2014;7:15-27.

27. Abdoon A-MMO, Alsharani AM. Prevalence and distribution of anopheline mosquitoes in malaria endemic areas of Asir region, Saudi Arabia. East Mediterr Health J. 2003;9:240-7.

28. Al Ahmed AM, Al Kuriji MA, Kheir SM, Al Sogoor DAD, Salama HAS. Distribution and seasonal abundance of mosquitoes (Diptera: Culicidae) in the Najran Region, Saudi Arabia. Stud Dipterol. 2010;17:13-27.

29. Abdullah MA, Merdan Al. Distribution and ecology of the mosquito fauna in the southwestern Saudi Arabia. J Egypt Soc Parsitol. 1995;25:815-37.

30. Alahmed AM, Al Kuriji MA, Kheir SM, Alahmedi SA, Al Hatabbi MJ, Al Gashmari MA. Mosquito fauna (Diptera: Culicidae) and seasonal activity in Makkah Al Mukarramah Region, Saudi Arabia. J Egypt Soc Parasitol. 2009:39:991-1013.

31. Wills WM, Jakob WL, Francy DB, Oertley RE, Anani E, Calisher CH, et al. Sindbis virus isolations from Saudi Arabian mosquitoes. Trans R Soc Trop Med Hyg. 1985;79:63-6.

32. Al-Kheerji MA. Survey and distribution of mosquito species (Diptera: Culicidae) and description of its habitat in Riyadh District, Kingdom of Saudi Arabia. M.Sc Thesis, King Saud University (in Arabic). Riyadh: Kingdom of Saudi Arabia; 2005.

33. Kheir SM, Alahmed AM, Al Kuriji MA, Al Zubyani SF. Distribution and seasonal activity of mosquitoes in Al Madinah Al Munwwrah [sic] Region, Saudi Arabia. J Egypt Soc Parasitol. 2010;40:215-27.

34. Kheir SM, Alahmed AM, Al-Kheriji MA, Al-Sekate SS. Distribution and seasonal activity of mosquitoes (Diptera: Culicidae) in Al-Qassim Region, Saudi Arabia. J King Saud Univ Agric Sci. 2011;23:39-48.

35. Alahmed AM. Mosquito fauna (Diptera: Culicidae) of the Eastern Region of Saudi Arabia and their seasonal abundance. J King Saud Univ Sci. 2012;24:55-62.

36. Ahmed MA, Shaalan EA, Aboul-Soud MAM, Tripet F, Al-Khedhairy AA. Mosquito vectors survey in the Al-Ahsaa district of eastern Saudi Arabia. J Insect Sci. 2011;11:1-11.

37. Büttiker W. Observation on urban mosquitoes in Saudi Arabia. In: Wittmer W, Büttiker W, editors. Fauna of Saudi Arabia, vol. 3. Basle: Pro Entomologia c/o Natural History Museum, Ciba Geigy Ltd.; 1981.

38. Alahmed AM, Kheir SM. Seasonal activity of some haematophagous insects in the Riyadh Region, Saudi Arabia. J Saudi Soc Agric Sci. 2005:4:95-105.

39. El Khereji MA, Alahmed AM, Kheir SM. Survey and seasonal activity of adult mosquitoes (Diptera: Culicidae) in Riyadh City, Saudi Arabia. Res Bull Food Sci Agric Res Center King Saud Univ. 2007;152:5-17.

40. Shaalan EA-S, Abdelsalam S, Elmenshawy O, Al-Kahtani MA. Mosquito vectors survey reveals new record of Culiseta subochrea in Al-Ahsa Oasis, Saudi Arabia. Asian Pac J Trop Dis. 2017;7:106-11.

41. Hassan MI, Al Ashry HA-H, Shobrak M, Kenawy MA. Field studies on mosquitoes (Diptera: Culicidae) in the Western Coast of Saudi Arabia: influence of temperature, $\mathrm{pH}$ and salinity of the breeding water on larval abundance. Greener J Biol Sci. 2016;6:95-102.

42. El-Badry AA, Al-Ali KH. Prevalence and seasonal distribution of dengue mosquito, Aedes aegypti (Diptera: Culicidae) in Al-Madinah Al-Munawwarah, Saudi Arabia. J Entomol Sci. 2010;7:80-8.

43. Sowilem MM, Kamal HA, Khater El. Life table characteristics of Aedes aegypti (Diptera: Culicidae) from Saudi Arabia. Trop Biomed. 2013;30:301-14.

44. Mahyoub JA, Al-Harbi OS, Al-Ghamdi KM, Mangoud AAH, Al-Solami HM. Population dynamics of different mosquito genera and species in Makkah city, Saudi Arabia. Biosci Biotechnol Res Commun. 2015;8:116-25.

45. Naeem M, Alahmed AM, Kheir SM, Sallam MF. Spatial distribution modeling of Stegomyia aegypti and Culex tritaeniorhynchus (Diptera: Culicidae) in Al-bahah Province, Kingdom of Saudi Arabia. Trop Biomed. 2016;33:295-310. 
46. Al Ali KH, El-Badry AA, Al Ali M, El-Sayed WSM, El-Beshbishy HA. Phylogenetic analysis of Aedes aegypti based on mitochondrial ND4 gene sequences in Almadinah, Saudi Arabia. Iran J Biotechnol. 2016;14:e1329.

47. Al-Azab AM, Al-ghamdi KM, Al-hudaib K, Zaituon AA, Shaheen MA, ElAraby W. Morphological and molecular identification of dengue fever vector Aedes aegypti (Diptera: Culicidae) in Jeddah Governorate-Saudi Arabia. J Pure Appl Microbiol. 2013;7:1391-400.

48. Al-Ghamdi KM, Al-Azab AM, Khormi HM, Kumar L, Mahyoub JA. Monitoring larval populations of Aedes aegypti in different residential districts of Jeddah governorate, Saudi Arabia. J Food Agric Environ. 2014;12:448-52.

49. Aziz AT, Dieng $\mathrm{H}$, Ahmad AH, Mahyoub JA, Turkistani AM, Mesed $\mathrm{H}$, et al. Household survey of container-breeding mosquitoes and climatic factors influencing the prevalence of Aedes aegypti (Diptera: Culicidae) in Makkah City, Saudi Arabia. Asian Pac J Trop Biomed. 2012;2:849-57.

50. Godsey MS Jr, Abdoon A-MM, Savage HM, Al-Shahrani AM, Al-Mazrou Y, Al-Jeffri MH, et al. First record of Aedes (Stegomyia) unilineatus in the Kingdom of Saudi Arabia. J Am Mosq Control Assoc. 2003;19:84-6.

51. Al-Ghamdi K, Alikhan M, Mahyoub J, Afifi ZI. Studies on identification and population dynamics of anopheline mosquitoes from Jeddah Province of Saudi Arabia. Biosci Biotechnol Res Commun. 2008;1:19-24.

52. Nanda N, Yadav RS, Subbarao SK, Joshi H, Sharma VP. Studies on Anopheles fluviatilis and Anopheles culicifacies sibling species in relation to malaria in forested hilly and deforested riverine ecosystems in northern Orissa, India. J Am Mosq Control Assoc. 2000;16:199-205.

53. Kar I, Subbarao SK, Eapen A, Ravendaran J, Satyanarayana TS, Raghavendra $K$, et al. Evidence for a new malaria vector species, species $E$, within the Anopheles culicifacies complex (Diptera: Culicidae). J Med Entomol. 1999:36:595-600.

54. Goswami G, Singh OP, Nanda N, Raghavendra K, Gakhar SK, Subbarao SK. Identification of all members of the Anopheles culicifacies complex using allele-specific polymerase chain reaction assays. Am J Trop Med Hyg. 2006;75:454-60.

55. Daggy RH. Malaria in oases of eastern Saudi Arabia. Am J Trop Med Hyg. 1959:8:223-91.

56. Al-Sheik AA. Larval habitat, ecology, seasonal abundance and vectorial role in malaria transmission of Anopheles arabiensis in Jazan Region of Saudi Arabia. J Egypt Soc Parasitol. 2011;41:615-34.

57. Alzahrani MH, McCall P, Hassan A, Omar Al, Abdoon AM. Impact of irrigation system on malaria transmission in Jazan Region, Saudi Arabia. Open J Trop Med. 2017;1:OJTM-1-102.

58. Dafalla OM, Alsheikh AA, Abakar AD, Mohammed WS, Elrahman SHA, Noureldin EM. Detection of Plasmodium in Anopheles arabiensis using nested-PCR in Jazan region, Saudi Arabia. Biosci Biotechnol Res Commun. 2017;10:32-9.

59. Munawar K. Molecular phylogenetics of some anopheline mosquitoes from Saudi Arabia. M.Sc thesis, King Saud University. Riyadh: Kingdom of Saudi Arabia; 2014.

60. Davidson G. Distribution records of member species of the Anopheles gambiae complex (identifications up to May 1966). WHO/Mal/66.570, WHO/Nector Control/66.215. Geneva: World Health Organization; 1966.

61. Alahmed AM, Kheir SM, Al Kuriji MA, Sallam MF. Breeding habitats characterization of Anopheles mosquito (Diptera: Culicidae) in Najran Province, Saudi Arabia. J Egypt Soc Parasitol. 2011;41:273-86.

62. Alahmed AM, Naeem M, Kheir SM, Sallam MF. Ecological distribution modeling of two malaria mosquito vectors using geographical information system in Al-Baha Province, Kingdom of Saudi Arabia. Pak J Zool. 2015:47:1797-806.

63. Abdoon A-MMO. First record of three Afrotropical Culex species (Diptera: Culicidae) in Saudi Arabia. Ann Med Entomol. 2004;13:1-9.

64. Al-Ali KH, El-Badry AA, Eassa AHA, Al-Juhani AM, Al-Zubiany SF, Ibrahim E-KD. A study on Culex species and Culex transmitted diseases in AlMadinah Al-Munawarah, Saudi Arabia. Parasitol United J. 2008;1:101-8.

65. Kenawy MA, Al Ashry HAH, Shobrak MY. Analysis of the interspecific association between larvae of Culex pipiens and Culex quinquefasciatus, the common and medically important mosquito species (Diptera: Culicidae) in Hail Region, Kingdom of Saudi Arabia. Asian Pac J Trop Dis. 2017;7:788-91.

66. Hassan MI, Kenawy MA, Al Ashry HA, Shobrak M. Influence of climatic factors on the abundance of Culex pipiens and $C x$. quinquefasciatus
(Diptera: Culicidae) adults in the Western Coast of Saudi Arabia. J Entomol Acarol Res. 2017;49:6442.

67. Al Ashry HA, Kenawy MA, Shobrak M. Ecological aspects of the Bancroftian filariasis vectors, Culex pipiens and Cx. quinquefasciatus (Diptera: Culicidae) in Hail. Saudi Arabia. Int J Mosa Res. 2018;5:25-32.

68. Sallam MF, Al Ahmed AM, Abdel-Dayem MS, Abdullah MAR. Ecological niche modeling and land cover risk areas for Rift Valley fever vector, Culex tritaeniorhynchus Giles in Jazan, Saudi Arabia. PLoS ONE. 2013;8:e65786.

69. Stone A. A new subspecies of Uranotaenia unguiculata Edwards from Arabia (Diptera: Culicidae). Proc Entomol Soc Wash. (for 1960). 1961;62:249.

70. Coluzzi M, Sabatini A, della Torre A, Di Deco MA, Petrarca V. A polytene chromosome analysis of the Anopheles gambiae species complex. Science. 2002;298:1415-8.

71. Coetzee M, Hunt RH, Wilkerson R, della Torre A, Coulibaly MB, Besansky $\mathrm{NJ}$. Anopheles coluzzii and Anopheles amharicus, new members of the Anopheles gambiae complex. Zootaxa. 2013;3619:246-74.

72. Zahar AR. Part II. The WHO European Region and the WHO Eastern Mediterranean Region. Volume II. Applied field studies. Section III: Vector bionomics, malaria epidemiology and control by geographical areas. (B) Asia west of India. Geneva: Division of Vector Biology and Control \& World Health Organization; 1990.

73. Gillies MT, Coetzee M. A supplement to the Anophelinae of Africa south of the Sahara. Publ S Afr Inst Med Res. 1987:55:1-143.

74. WHO. Integrated vector management strategic framework for the Eastern Mediterranean Region 2004-2010. Cairo: World Health Organization, Regional Office for the Eastern Mediterranean; 2004.

75. WHO. World malaria report 2011. Geneva: World Health Organization; 2011.

76. Subbarao SK. Anopheline species complexes in Southeast Asia. Technical Publication, SEARO 18. New Delhi: World Health Organization, Regional Office for Southeast Asia; 1998.

77. Singh OP, Chandra D, Nanda N, Raghavendra K, Sunil S, Sharma SK, et al. Differentiation of members of the Anopheles fluviatilis species complex by an allele-specific polymerase chain reaction based on 285 ribosomal DNA sequences. Am J Trop Med Hyg. 2004;70:27-32.

78. Manonmani A, Townson H, Adeniran T, Jambulingam P, Sahu S, Vijayakumar T. rDNA-ITS2 polymerase chain reaction assay for the sibling species of Anopheles fluviatilis. Acta Trop. 2001;78:3-9.

79. Manonmani A, Nanda N, Jambulingam P, Sahu S, Vijayakumar T, Vani JR, et al. Comparison of polymerase chain reaction assay and cytotaxonomy for identification of sibling species of Anopheles fluviatilis (Diptera: Culicidae). Bull Entomol Res. 2003:93:169-71.

80. Naddaf SR, Oshaghi MA, Vatandoost H. Confirmation of two sibling species among Anopheles fluviatilis mosquitoes in south and southeastern Iran by analysis of cytochrome oxidase I gene. J Arthropod Borne Dis. 2012;6:144-8.

81. Nanda N, Singh OP, Dua VK, Pandey AC, Nagpal BN, AdakT, et al. Population cytogenetic and molecular evidence for existence of a new species in Anopheles fluviatilis complex (Diptera: Culicidae). Infect Genet Evol. 2013;13:218-23.

82. Naddaf SR, Oshaghi MA, Vatandoost H, Assmar M. Molecular characterization of Anopheles fluviatilis species complex in the Islamic Republic of Iran. East Mediterr Health J. 2003;9:257-65.

83. Manguin S, Garros C, Dusfour I, Harbach RE, Coosemans M. Bionomics, taxonomy, and distribution of the major malaria vector taxa of Anopheles subgenus Cellia in Southeast Asia: an updated review. Infect Genet Evol. 2008;8:489-503.

84. Singh OP, Goswami G, Nanda N, Raghavendra K, Chandra D, Subbarao SK. An allele-specific polymerase chain reaction assay for the differentiation of members of Anopheles culicifacies complex. J Biosci. 2004;29:275-80.

85. Goswami G, Raghavendra K, Nanda N, Gakhar SK, Subbarao SK. PCRRFLP of mitochondrial cytochrome oxidase subunit II and ITS2 of ribosomal DNA: markers for the identification of members of the Anopheles culicifacies complex (Diptera: Culicidae). Acta Trop. 2005;95:92-9.

86. Vatandoost H, Shahi H, Abai MR, Hanafi-Bojd AA, Oshaghi MA, Zamani G. Larval habitats of main malaria vectors in Hormozgan Province and their susceptibility to different larvicides. Southeast Asian J Trop Med Public Health. 2004;35:22-5. 
87. Subbarao SK, Vasantha K, Adak T, Sharma VP, Curtis CF. Egg-float ridge number in Anopheles stephensi: ecological variation and genetic analysis. Med Vet Entomol. 1987;1:256-71.

88. Trung HD, Van Bortel W, Sochantha T, Keokenchanh K, Quang NT, Cong LD, et al. Malaria transmission and major malaria vectors in different geographical areas of Southeast Asia. Trop Med Int Health. 2004;9:230-7.

89. Oshaghi MA, Taghilo B, Moradi MT, Vatandoost H. Detection of the Anopheles culicifacies complex, species A and B in Baluchistan using mtDNA PCR-RFLP assay; the first report of species B from Iran (in Persian). Hakim. 2004;7:35-42.

90. Azari-Hamidian S. Checklist of Iranian mosquitoes (Diptera: Culicidae). J Vector Ecol. 2007:32:235-42.

91. Suguna SG, Rathinam KG, Rajavel AR, Dhanda V. Morphological and chromosomal descriptions of new species in the Anopheles subpictus complex. Med Vet Entomol. 1994;8:88-94.

92. Surendran SN, Sarma DK, Jude PJ, Kemppainen P, Kanthakumaran N, Gajapathy K, et al. Molecular characterization and identification of members of the Anopheles subpictus complex in Sri Lanka. Malar J. 2013;12:304.

93. Sweet WC, Rao BA. Races of A. stephensi Liston, 1901. Ind Med Gaz. 1937;71:665-74

94. Rao BA, Sweet WC, Subba-Rao AM. Ova measurements of An. stephensi type and An. stephensi var. mysorensis. J Malar Inst India. 1938;1:261-6.

95. Nagpal BN, Srivastava A, Kalra NL, Subbarao SK. Spiracular indices in Anopheles stephensi: a taxonomic tool to identify ecological variants. J Med Entomol. 2003;40:747-9.

96. Tyagi V, Dhiman S, Sharma AK, Srivastava AR, Rabha B, Sukumaran D, et al. Morphometric and morphological appraisal of the eggs of Anopheles stephensi (Diptera: Culicidae) from India. J Vector Borne Dis. 2017;54:151-6.

97. Chavshin AR, Oshaghi MA, Vatandoost H, Hanafi-Bojd AA, Raeisi A, Nikpoor F. Molecular characterization, biological forms and sporozoite rate of Anopheles stephensi in southern Iran. Asian Pac J Trop Biomed. 2014:4:47-51

98. Alam MT, Bora H, Das MK, Sharma YD. The type and mysorensis forms of the Anopheles stephensi (Diptera: Culicidae) in India exhibit identical ribosomal DNA ITS2 and domain-3 sequences. Parasitol Res. 2008;103:75-80
99. Al-Eryani SMA, Kelly-Hope L, Harbach RE, Briscoe AG, Barnish G, Azazy $A$, et al. Entomological aspects and the role of human behaviour in malaria transmission in a highland region of the Republic of Yemen. Malar J. 2016;15:130.

100. Mattingly PF. Contributions to the mosquito fauna of Southeast Asia. XII. Illustrated keys to the genera of mosquitoes (Diptera, Culicidae). Contrib Am Entomol Inst. 1971;7(4):1-84.

101. Harbach RE. Culex pipiens Linnaeus: species versus species complex-taxonomic history and perspective. J Am Mosq Control Assoc. 2012;28:10-23.

102. Sundararaman S. Biometrical studies on intergradation in the genitalia of certain populations of Culex pipiens and Culex quinquefasciatus in the United States. Am J Hyg. 1949;50:307-14.

103. Barr AR. The distribution of Culexp. pipiens and C. p. quinquefasciatus in North America. Am J Trop Med Hyg. 1957;6:153-65.

104. Parrish DW. The mosquitoes of Turkey. Mosq News. 1959;19:264-6.

105. Gunay F, Alten B, Simsek F, Aldemir A, Linton Y-M. Barcoding Turkish Culex mosquitoes to facilitate arbovirus vector incrimination studies reveals hidden diversity and new potential vectors. Acta Trop. 2015:143:112-20.

106. Rueda LM, Pecor JE, Lowen RG, Carder M. New record and updated checklists of the mosquitoes of Afghanistan and Iraq. J Vector Ecol. 2008;33:397-402

107. Hasson RH. Mosquitos' [sic] species of Diyala province, Iraq. Int J Environ Agric Biotechnol. 2017;2:2121-6.

108. Knight KL. The mosquitoes of the Yemen. Proc Entomol Soc Wash. 1953;55:212-34.

109. Hopkins GHE. Mosquitoes of the Ethiopian Region I. Larval bionomics of mosquitoes and taxonomy of culicine larvae. 2nd ed. London: British Museum (Natural History); 1952.

\section{Publisher's Note}

Springer Nature remains neutral with regard to jurisdictional claims in published maps and institutional affiliations.
Ready to submit your research? Choose BMC and benefit from:

- fast, convenient online submission

- thorough peer review by experienced researchers in your field

- rapid publication on acceptance

- support for research data, including large and complex data types

- gold Open Access which fosters wider collaboration and increased citations

- maximum visibility for your research: over $100 \mathrm{M}$ website views per year

At $\mathrm{BMC}$, research is always in progress.

Learn more biomedcentral.com/submissions 